\title{
Determination of Sulfur Dioxide in Wine Using a Quartz Crystal Microbalance
}

\author{
M. Teresa Gomes,* Teresa A. Rocha, Armando C. Duarte, and J oão P. Oliveira \\ Department of Chemistry, University of Aveiro, 3810 Aveiro, Portugal
}

A new method for the analysis of both total and bound $\mathrm{SO}_{2}$ in wine is proposed, based on a quartz crystal microbalance (QCM), and it is compared with the widely used Ripper method. The proposed method is faster than the Ripper's, and the instrumentation is either homemade or widely available. When both methods are applied to the same sample, the results obtained using the QCM method are bracketed in an interval less than one-tenth the size of that obtained using the Ripper method. Although the $\mathrm{SO}_{2}$ concentrations found using the QCM method correlate well with the ones obtained with the Ripper method, the results are systematically higher, which can be explained as due to the absence of interferences known to affect the Ripper method.

Sulfur dioxide is a powerful antioxidant and antiseptic, and it is widely used in wine making as a preservative. In wine, $\mathrm{SO}_{2}$ occurs in two different forms: free and bound. Only free $\mathrm{SO}_{2}$ has antiseptic and reducing properties, although some of the binding reactions of $\mathrm{SO}_{2}$ are reversible and can be seen as a sink of free $\mathrm{SO}_{2}$ that can compensate for its decrease. ${ }^{1}$

The presence of $\mathrm{SO}_{2}$ in wine can affect its bouquet and taste and can be hazardous to human health. $\mathrm{SO}_{2}$ is an important analytical parameter in wine quality control, and there are regulations that establish maximum allowable contents. The most widely used analytical methods rely upon either a time-consuming distillation 2,3 or an iodometric titration. In the widely used Ripper method, ${ }_{1}^{1,3}$ free $\mathrm{SO}_{2}$ is determined by an iodometric titration of an acidified wine sample, corrected by a titration of another wine sample in which an excess of ethanol was combined with free $\mathrm{SO}_{2}$. Bound $\mathrm{SO}_{2}$ can be calculated by iodometric titration of the sample used for the free $\mathrm{SO}_{2}$ determination, after double alkaline hydrolyses. Although titration is considered a fast method, it has poor precision and high systematic errors, especially for red wines. ${ }^{4}$ The Paul method, based on $\mathrm{SO}_{2}$ trapping and oxidation in a $\mathrm{H}_{2} \mathrm{O}_{2}$ solution, requires careful control of the operating methodology and of the apparatus specifications, and it is, in practice, only used to confirm the results of the iodometric method. ${ }^{1}$

Lately, several flow injection anlaysis methodologies associated with colorimetric, potentiometric, or chemiluminescent detection have been proposed. One of the drawbacks of these methodolo-

(1) Curvelo-Garcia, A. S. Controlo da qualidade dos vinhos; Instituto da vinha e do vinho: Lisboa, Portugal, 1988

(2) Official Methods of Analysis, 15th ed.; AOAC: Arlington, VA, 1990.

(3) Recuil des Méthodes Internationales d'Analyse de Vins, 5th ed.; Office International de la Vigne et du Vin: Paris, 1978.

(4) Vahl, J. M.; Converse, J. E. J. Assoc. Off. Anal. Chem. 1980, 63, 194-199.

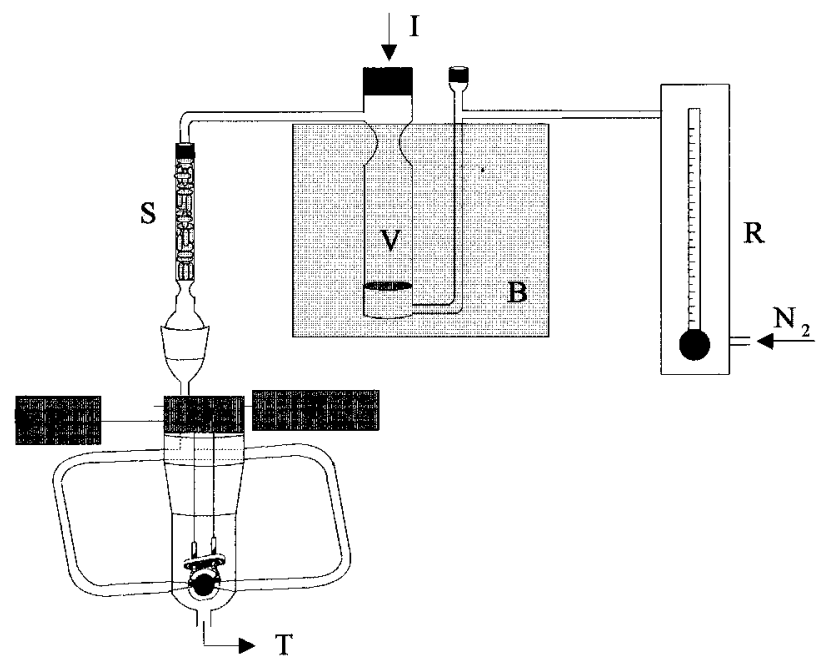

Figure 1. Experimental layout ( $P$, power supply; $O$, oscillator; $F$, frequency meter; $\mathrm{T}$, waste; $\mathrm{S}$, $3 \AA$ A molecular sieves; $\mathrm{V}$, reaction cell; $B$, thermostatic bath; I, sample introduction; $R$, flowmeter).

gies is the gas diffusion step, since the diffusion of $\mathrm{SO}_{2}$ of wine is limited due to a matrix effect. ${ }^{5}$

In conclusion, there is still a need for a fast, inexpensive, and reliable method for analysis of $\mathrm{SO}_{2}$ in both white and red wines.

\section{EXPERIMENTAL SECTION}

Chemicals and Materials. All reagents were analytical grade and were used without further purification. Standardized sulfite solutions were freshly prepared with deaerated Milli-Q water. Synthetic wine was prepared according to Lázaro et al. ${ }^{6}$

Nitrogen was R grade from "ArLíquido". The wines were all still white wines produced in Portugal.

The piezoelectric crystals were $9 \mathrm{MHz}$, AT-cut HC-6/ U with gold electrodes (International Crystal Manufacturing Co. Inc.).

Apparatus. The experimental setup of the quartz crystal microbalance (QCM) apparatus is shown in Figure 1 and consists mainly of a piezoelectric crystal housed in a cell that splits the gas flow in two and leads each of the streams to the center of each of the crystal faces. Before reaching the cell, the nitrogen flow is controlled with a variable area flowmeter (Cole-Parmer) and enters the bottom of a thermostated glass cell, where a medium-size sintered glass plate sustains the mercury solutions and allows the gas to pass through it, displacing the mercury vapor. The gas is then dried in a $3 \AA$ molecular sieve column

(5) Granados, M.; M aspoch, S.; Blanco, M. Anal. Chim. Acta 1986, 179, 445451.

(6) Lázaro, F.; Luque de Castro, M. D.; Valcárcel, M. Anal. Chem. 1987, 59, 950-954. 


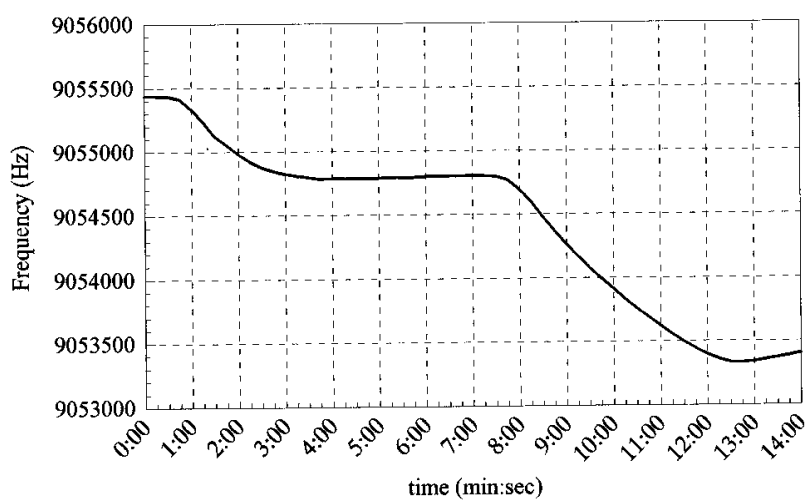

Figure 2. Frequency change due to the $\mathrm{Hg}(\mathrm{I})$ solution and upon the introduction of sulfite solution.

before its entrance into the crystal cell. For safety reasons, the gas exiting the crystal cell bubbles in a $\mathrm{KMnO}_{4} / \mathrm{H}_{2} \mathrm{SO}_{4}$ trap solution.

The wine cell has a screw top to introduce the mercury solution, with a silicone ring (G18) that allows the passage of a micropipet tip, used for the introduction of wine or standard sulfite solutions.

The crystal oscillator circuit based on TTL inverter gates and the power supply were both home-made. The frequency was measured with a frequency meter.

Procedure. The methodology is based on the disproportionation of mercury (I) according to the following reaction:

$$
\mathrm{Hg}_{2}{ }^{2+} \rightleftharpoons \mathrm{Hg}^{2+}+\mathrm{Hg}^{0}
$$

The mercury vapor, carried by a nitrogen flow, amalgamates on the gold electrodes of the piezoelectric crystal, and a frequency decrease is observed. ${ }^{7}$ Figure 2 shows a plot of the crystal frequency when $10 \mathrm{~mL}$ of $4 \times 10^{-3} \mathrm{M} \mathrm{HgNO}_{3}$ is introduced in the thermostated cell $\left(27^{\circ} \mathrm{C}\right)$, with a nitrogen flow of $54 \mathrm{~mL} \mathrm{~min}{ }^{-1}$. Seven minutes after the introduction of the mercury solution, in the region of a frequency plateau, a standardized sulfite solution is added, and a second frequency decrease is observed. This frequency decrease is proportional to the amount of $\mathrm{SO}_{2}$, because the formation of $\mathrm{Hg}(\mathrm{II})$ complexes promotes the mercury disproportionation: 8

$$
2 \mathrm{SO}_{2}+2 \mathrm{H}_{2} \mathrm{O}+\mathrm{Hg}_{2}{ }^{2+} \rightleftharpoons \mathrm{Hg}\left(\mathrm{SO}_{3}\right)_{2}^{2-}+\mathrm{Hg}^{0}+4 \mathrm{H}^{+}
$$

After each sample, the mercury present in the electrodes was driven off by heating the crystals for $2 \mathrm{~h} 40 \mathrm{~min}$. The cell was washed, and pure nitrogen was passed through the entire apparatus to clean it from other gases.

A calibration curve was obtained upon introducing, with a calibrated micropipet, $50.003 \mu \mathrm{L}$ aliquots of standardized solutions with different sulfite concentrations.

The wine analyses for total $\mathrm{SO}_{2}$ are performed by introducing over the mercury solution, and without pretreatment, quantities of wine that cause a frequency decrease near the centroid of the linear calibration zone. For the analysis of bound $\mathrm{SO}_{2}$, the free

(7) Suleiman, A. A.; Guilbault, G. G. Anal. Chem. 1984, 56, 2964-2966.

(8) M arshall, G.; M idgley, D. Anal. Chem. 1982, 54, 1490-1494.

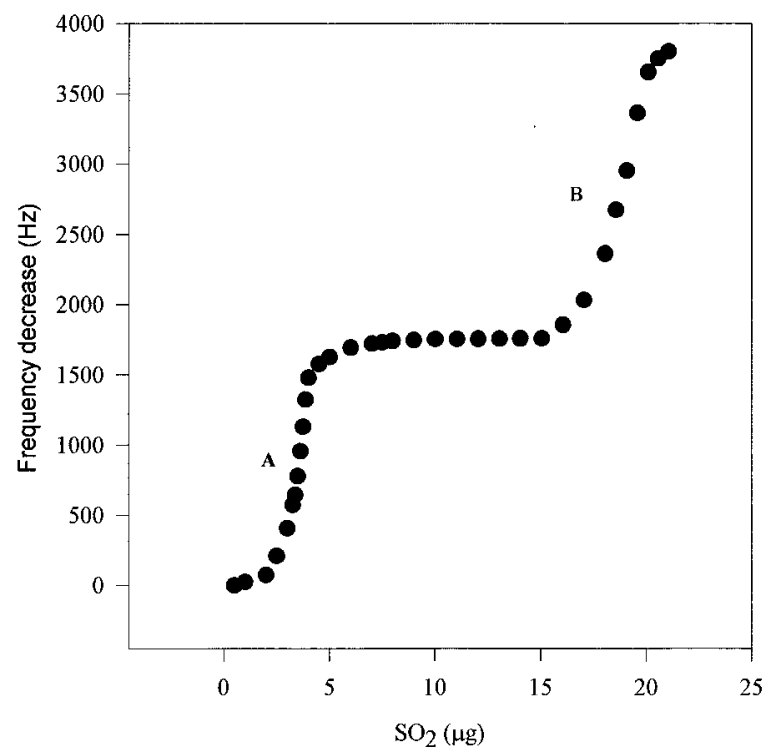

Figure 3. Calibration curve.

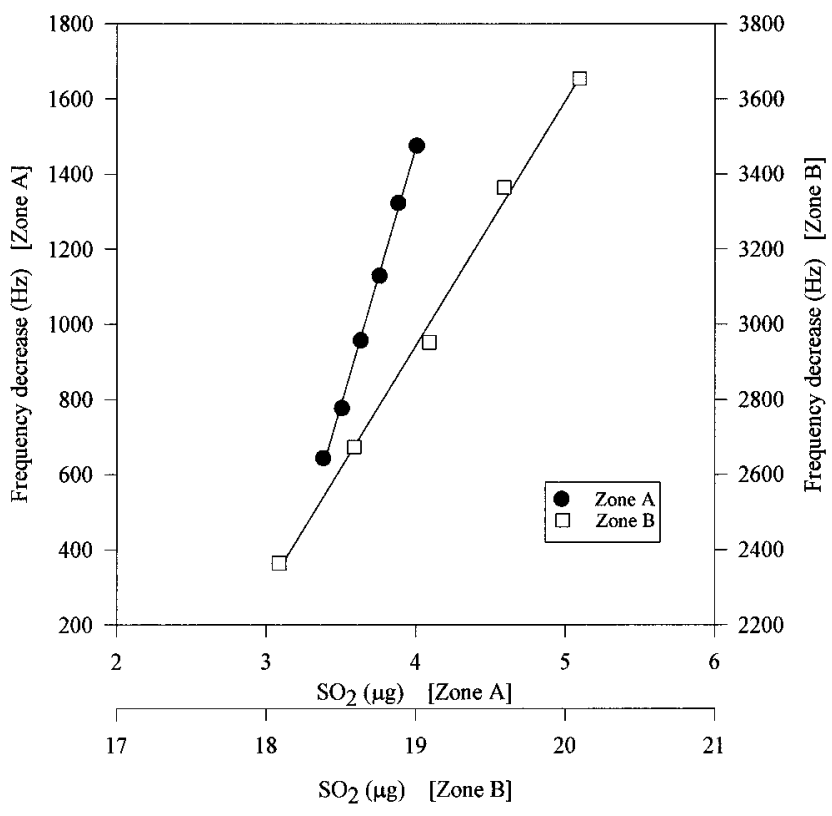

Figure 4. A and $\mathrm{B}$ zones of the calibration curve.

$\mathrm{SO}_{2}$ is displaced under nitrogen, prior to the sample introduction, and, as before, the amount of wine is chosen according to its $\mathrm{SO}_{2}$ content.

\section{RESULTS AND DISCUSSION}

The calibration curve displayed in Figure 3 shows two linear regions separated by a plateau. According to the binary diagram $\mathrm{Au}-\mathrm{Hg},{ }^{9}$ the plateau of the calibration curve can correspond to the presence of the $\mathrm{Au}_{2} \mathrm{Hg}$ phase. Both linear regions could be used for quantitative analysis, although Figure 4 clearly shows that zone A has a larger slope than zone B. A larger slope is correlated with a greater sensitivity, and this is why zone $A$ was chosen as the working calibration line. The calibration line of zone $\mathrm{A}$ is fitted by the equation $\Delta \mathrm{F}=1363.60 \mathrm{~m}-3986.0\left(\mathrm{r}^{2}=\right.$ 0.9979), where $\Delta \mathrm{F}$ represents the frequency decrease $(\mathrm{Hz})$ and $\mathrm{m}$ the mass of $\mathrm{SO}_{2}(\mu \mathrm{g})$.

(9) ASM Handbook, Vol. 3. Alloy Phase Diagram, 9th ed.; ASM International, The M aterials Information Society: M aterials Park, OH, 1992. 
Table 1. Comparison of the Results Obtained Using the QCM and Ripper Methods

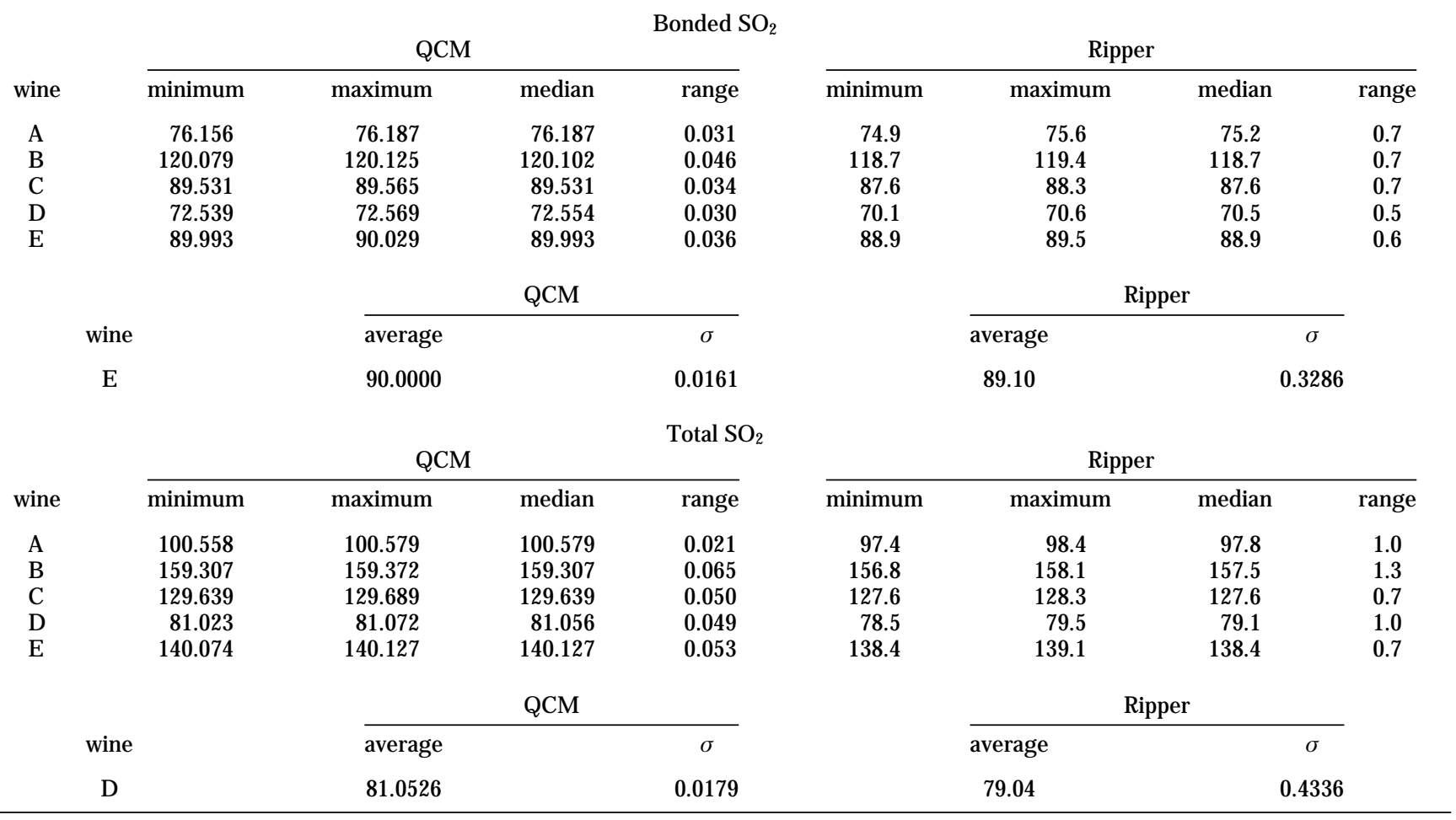

The calibration curve does not depend on the volume of sample introduced for the range of volumes useful for the analyzed wines. Since the calibration curve also does not depend on the crystal used, the analytical process can be run on a nonstop basis during the slow cleaning procedure of the previously used crystals. Each crystal can be used to perform an average of 35 analyses, after which its frequency experiences a sudden rise and an unbearable instability that precedes its lack of vibration. This phenomenon can be explained by the poor adhesion of some electrode segments, which become loose due to thermal shocks. ${ }^{10}$

Five different bottles of wine were analyzed by the QCM and the Ripper methods. Each analysis was repeated five times. A normality test, the Kolmogorov-Smirnov, and a test for the variance comparison, the Levene median, were performed for all sets of results. ${ }^{11}$ For a confidence level of $99 \%$ excepting for wine $\mathrm{E}$ for bound $\mathrm{SO}_{2}$ and wine $\mathrm{D}$ for total $\mathrm{SO}_{2}$, either the data fail the normality test, or there are statistically significant differences in the variances. The M ann-Witney rank sum test was performed in all cases, but for the two exceptions, the paired Student's t test was used for comparison of the means.

Table 1 shows the results of the statistical analyses for the bound and total $\mathrm{SO}_{2}$ for five different wines, obtained by the proposed QCM method and by the Ripper method. For a confidence level $>99 \%$ it was found that the differences in the median, or average values, were in all cases greater than would be expected by chance. The results show that the Ripper method consistently gives lower $\mathrm{SO}_{2}$ concentrations than the QCM method. The lower results of the Ripper method can be caused by the oxidation of sulfite in the alkalinization process and by the

(10) Dworsky, L. IEEE Trans. Ultrason., Ferroelectrics F requency Control 1994, $41,261-268$.

(11) SigmaStat for Windows version 1.0 software package, J andel Scientific, San Rafael, CA, 1994

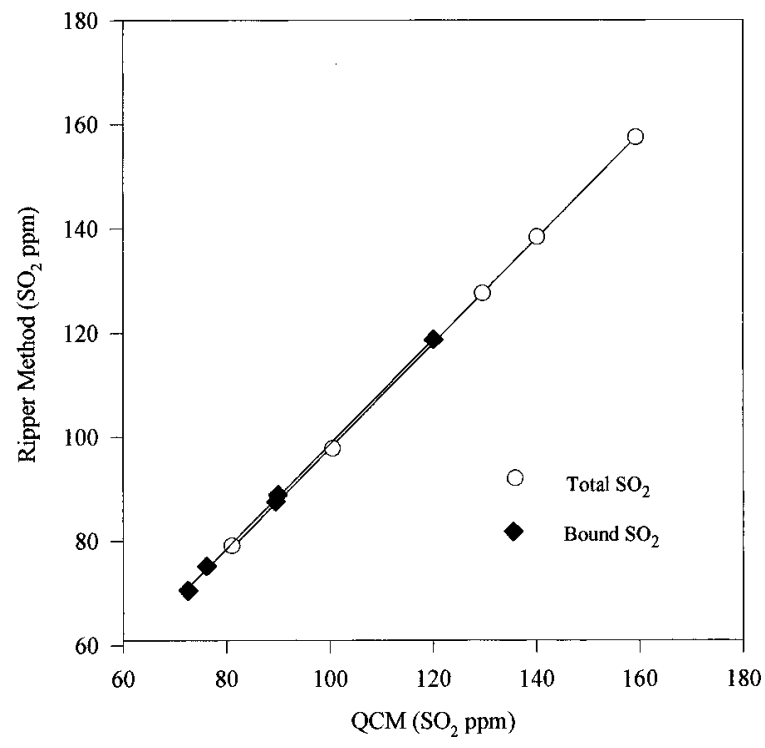

Figure 5. Correlation of the results obtained using the QCM and the Ripper methods for total and bound $\mathrm{SO}_{2}$.

recombination with ethanal of the $\mathrm{SO}_{2}$ freed by the acid. ${ }^{1}$ It is also well known that the procedure used in the Ripper method to correct for the presence of certain substances oxidized by the iodide is excessive. ${ }^{1}$

The results show that, for the same sample, the range of concentrations is always narrower when using the QCM method than when using the Ripper method. Therefore, one can conclude that using the quartz crystal microbalance allows higher precision than is possible with the Ripper method.

Figure 5 shows the correlations of the results obtained by both methods. The square of the correlation coefficient is 0.9999 for 
total $\mathrm{SO}_{2}$ and 0.9994 for bound $\mathrm{SO}_{2}$. For bound $\mathrm{SO}_{2}$, the slope $\left(a_{b}\right)$ and intercept $\left(b_{b}\right)$ of the regression line, with $95 \%$ confidence limits, are respectively

$$
a_{b}=1.0041 \pm 0.0467 ; \quad b_{b}=1.8608 \pm 4.2623
$$

while for total $\mathrm{SO}_{2}$, the slope $\left(a_{t}\right)$ and intercept $\left(b_{t}\right)$ of the regression line, with $95 \%$ confidence limits, are respectively

$$
a_{t}=1.0068 \pm 0.0212 ; \quad b_{t}=-2.8973 \pm 2.6514
$$

As both slopes are close to the unity, there is no evidence of systematic errors. For total $\mathrm{SO}_{2}$, the small but negative intercept shows that the microbalance results are higher than the ones obtained with the Ripper method.

As it is known that $\mathrm{OH}$ groups can bind to the surface of gold electrodes, ${ }^{12}$ the main hydroxylic volatile wine constituents were mixed with synthetic wine, without $\mathrm{SO}_{2}$, and analyzed to test for interferences. The tests were performed for ethanol, methanol, ethanal, 2-methyl-1-propanol, 3-methyl-1-butanol, and acetic acid, in quantities equal to or higher than the normal wine contents or the legal limits. Each compound tested was independently mixed with synthetic wine. The quantity of the "test wine" introduced in the cell was similar to the quantities used in the analyses of the samples. No frequency decrease was obtained with any of the tested compounds.

As the proposed method responds to total $\mathrm{SO}_{2}$, another test was performed to make sure that there is no discrimination between free and bound $\mathrm{SO}_{2}$. Table 2 shows the results of the analyses of five replicates of a sample of synthetic wine containing

(12) Tsionsky, V.; Gileady, E. Langmuir 1994, 10, 2830-2835.
Table 2. QCM Results $\left(\mathrm{SO}_{2}, \mathrm{ppm}\right)$ for a Synthetic Wine Containing 159.34 ppm $\mathrm{SO}_{2}$, with and without Ethanal without ethanal

159.40

159.37

159.37

159.37

159.34 with ethanal

159.37

159.37

159.34

159.37

159.34
$159.34 \mathrm{ppm}$ of $\mathrm{SO}_{2}$ before and $45 \mathrm{~min}$ after the addition of $75 \mathrm{ppm}$ of ethanal. There is no difference between the results, indicating that the method does not differentiate between the two $\mathrm{SO}_{2}$ forms.

\section{CONCLUSIONS}

As a general conclusion, it can be said that using the quartz crystal microbalance allows the direct determination of total $\mathrm{SO}_{2}$ without the need of a hydrolysis step. Furthermore, the stability of the calibration curve, the fact that the crystal does not influence the results, and the short time of the analysis ( $<15 \mathrm{~min}$ for response, and $5-10 \mathrm{~min}$ to wash the cell and flush the apparatus with nitrogen) make it a very fast technique. It is an inexpensive method and has a better precision than the Ripper method, and the results correlate well with the ones obtained with the Ripper method, although they are higher for total $\mathrm{SO}_{2}$, and can be applied to both white and red wines.

Received for review October 24, 1995. Accepted February 1,1996 . $^{\otimes}$

\section{AC9510548}

${ }^{\otimes}$ Abstract published in Advance ACS Abstracts, M arch 1, 1996. 